\title{
Investigation of perfluorinated compounds (PFCs) in mollusks from coastal waters in the Bohai Sea of China $\uparrow$
}

\author{
Yuanyuan Pan, Yali Shi, Yawei Wang, Yaqi Cai* and Guibin Jiang \\ Received 11th May 2009, Accepted 15th September 2009 \\ First published as an Advance Article on the web 14th October 2009 \\ DOI: $10.1039 / b 909302 h$
}

\begin{abstract}
The occurrence of perfluorinated compounds (PFCs) in the Bohai Sea region, a semi-enclosed bay in north China, was assessed in this present study. Nine different PFCs were measured in eleven mollusk species (soft tissues) collected from 9 coastal cities. Most of the analyzed PFCs could be detected in the samples, with perfluorooctanoic acid (PFOA) as the prominent PFC, although perfluorooctane sulfonate (PFOS) has been shown to be more bioaccumulative than PFOA by other studies. The detection frequency of PFOA was 72\%. Significantly high levels of PFOA were found in Mactra veneriformis, Scapharca subcrenata and Meretrix meretrix Linnaeus, with mean concentrations at 31.3 $\mathrm{ng} \mathrm{g}^{-1}, 15.0 \mathrm{ng} \mathrm{g}^{-1}$ and $12.2 \mathrm{ng} \mathrm{g}^{-1}$, respectively (dry weight). The distinct distribution of PFOA in these species can be used as a potential indicator of the bioaccumulation capacity. PFOS was found in mollusks at lower concentrations and frequency (61\%). Positive linear regressions were found between perfluoroheptanoic acid (PFHpA), PFOA and PFOS $(p<0.01, n=123)$, suggesting that these compounds may come from a similar origin of exposure and accumulation. It is suspected that higher emissions from usage or production of PFC related products might exist in Shouguang City, since the majority of the elevated concentrations of PFOA or PFOS were found in Shouguang. As the PFC concentrations in mollusks were comparatively low, humans are not likely to be at risk of PFC exposure through the daily consumption of these seafoods.
\end{abstract}

\section{Introduction}

Perfluorinated compounds (PFCs) are a group of emerging and ubiquitous organic pollutants in the environment. Due to their environmental persistency and potential toxicity to humans and organisms, 3M, the prior major manufacturer of perfluorooctane sulfonate (PFOS) related compounds, announced the phase-out of PFOS production in 2000. However, because of their unique properties, PFCs are still extensively employed in numerous consumer and industrial applications. ${ }^{1,2}$ The long-term manufacture and use, which can trace back to the 1950s, are likely to be responsible for their emission and widespread occurrence in the environment. ${ }^{3}$

State Key Laboratory of Environmental Chemistry and Ecotoxicology, Research Center for Eco-Environmental Science, Chinese Academy of Sciences, P.O. Box 2871, Beijing, 100085, China. E-mail: caiyaqi@rcees. ac.cn; Fax: +861062849182 ; Tel: +861062849239

$\uparrow$ Electronic supplementary information (ESI) available: Further experimental results. See DOI: 10.1039/b909302h
With the ever increasing research on PFCs, particularly since $2002,{ }^{4}$ scientists have begun to obtain gradual understanding of the environmental distribution and toxicity of PFCs, although the specific mechanisms remained ambiguous. PFOS and perfluorooctanoic acid (PFOA) have been detected in water (rain, river, wastewaters and sea), ${ }^{5}$ foodstuff (fish, seafood and milk), ${ }^{6}$ humans (blood, serum and human milk) ${ }^{7}$ and animals ${ }^{8}$ (birds, panda, bear) from America, Canada, Spain, Germany, Japan, Korea and China, and even in the Arctic region. ${ }^{9}$ Several laboratory experiments have shown that PFOS can cause developmental and reproductive effects and affect the neuroendocrine system in rodents; ${ }^{10}$ the steroid hormone level was also found to be affected in fish after exposure to PFCs. ${ }^{11} \mathrm{PFC}$ concentrations in human blood have been assumed to be negatively associated with birth weight, ${ }^{12}$ although the toxicity of PFCs to humans is still being debated. ${ }^{13}$

PFCs have been reported at higher concentrations in urban wastewater than in the countryside, indicating urban activities are important sources of PFCs besides industrial emissions. ${ }^{14,15}$

\section{Environmental impact}

Perfluorinated compounds are extremely persistent and bioaccumulative, their occurrence and fate in the environment are of great concern. The aquatic environment is believed to play an important role in the transformation and diffusion of perfluorinated compounds, the data of perfluorinated compounds distribution is essential to estimate the pollution and the possible influence on wildlife or humans. The significance of the present paper is that for the first time we find the existence of perfluorinated compounds in biota from coastal areas in the Bohai Sea of China. And the article has added precious knowledge to the perfluorinated compounds research of the world and can be further considered as favorable proof of the widespread contamination of PFCs in the environment. 
Diffusion of various related volatile fluorinated precursors and telomer alcohols can also lead to environmental contamination of PFCs. ${ }^{16}$ In China, studies on PFCs have just recently begun, but those few works revealed that PFCs were found in water, ${ }^{6}$ and seafood ${ }^{17,18}$ from south China and Dalian. ${ }^{19}$

The Bohai Sea, an important regional economic center in north China, is a semi-enclosed water body with a coastal line nearly $3800 \mathrm{~km}$ long. Numerous studies on the distribution of persistent organic pollutants (POPs) and heavy metals have been conducted in this region, revealing the unfavorable effects brought along with the dense urban activities and the rapid economic development during the past several decades. ${ }^{\mathbf{2 0 - 2 2}}$ However, only a limited number of studies on PFC pollution in this area have been conducted.

According to previous investigations, PFOS and PFOA can strongly adsorb onto sediment and sludge. ${ }^{23,24}$ Since mollusks are benthic species and are more susceptible to the pollution around its habitat, they could be useful in reflecting the regional pollution situation. Mollusks in the Bohai area have consequently also been selected as bio-indicators for several contaminants including organohalogen compounds and heavy metals. ${ }^{20,25}$ The present study aims to comprehensively investigate the pollution levels of PFCs in the Bohai Sea region. Nine PFCs were analyzed in mollusks of eleven species collected from coastal water of the Bohai Sea, including clams, oysters, mussels and other common species.

\section{Experimental}

Mollusks were collected from nine coastal cities of the Bohai Sea region in late July to early August 2006 and 2007: Weihai (WH), Yantai (YT), Penglai (PL), Shouguang (SG), Tianjin (TJ), Beidaihe (BDH), Huludao (HLD), Yingkou (YK), and Dalian (DL), as shown in Fig. 1. All collected samples were pooled based on species once collected and transported according to the procedure described in an earlier report. ${ }^{26}$ Generally 137 pooled

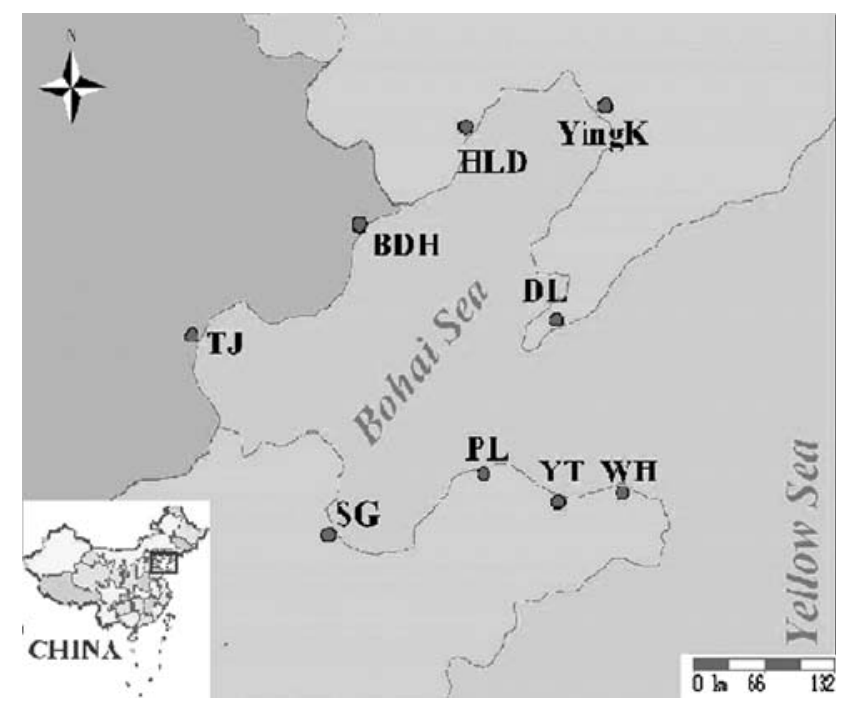

Fig. 1 The sampling sites along the coastline of Bohai Sea in China: Dalian (DL), Yingkou (YK), Huludao (HLD), Beidaihe (BDH), Tianjin (TJ), Shouguang (SG), Penglai (PL), Yantai (YT), Weihai (WH). samples were composed of 11 species, which were Crassostrea talienwhanensis (Ost), Chlamys farreri (Chl), Amusium (Amu), Scapharca subcrenata (Sca), Meretrix meretrix Linnaeus (Mer), Mactra veneriformis (Mac V), Mactra chinensis (Mac C), Mya arenaria (Mya), Neverita didyma (Nev), Rapana venosa (Rap) and Mytilus edulis (Myt). All the samples were prepared after arriving at the laboratory as follows: (i) soft tissue homogenate was freeze-dried and; (ii) ground into fine powder, then finally; (iii) all samples were wrapped with aluminum foil and stored at $-20{ }^{\circ} \mathrm{C}$ until chemical analysis. All equipment and storage containers during the sample collection, transportation and preparation were rinsed with methanol and water before use to avoid any analytical interference or cross contamination.

Samples were pretreated by alkaline digestion and solid phase extraction, which has been described elsewhere except for some modification. ${ }^{17}$ Generally, $0.2 \mathrm{~g}$ of tissue sample was spiked with $10 \mathrm{ng}$ of internal standard and aged for $10 \mathrm{~min}$. Eight milliliters of $10 \mathrm{mM} \mathrm{NaOH}$ (in methanol) was added to the aged sample. After shaking (250 rpm) for $16 \mathrm{~h}$ and centrifugation, $4 \mathrm{~mL}$ of supernatant was diluted with $36 \mathrm{~mL}$ water. Then, the dilution was loaded onto a preconditioned Oasis ${ }^{\circledR}$ WAX cartridge (6 cc, $150 \mathrm{mg}$; Waters Corp. Milford, USA). Target analytes were eluted by $4 \mathrm{~mL}$ methanol and $4 \mathrm{~mL}$ ammonium hydroxide $(0.1 \%$ in methanol). The $8 \mathrm{~mL}$ eluate was concentrated to $1 \mathrm{~mL}$ under a nitrogen stream. The final extraction was centrifuged (10 000 $\mathrm{rpm}$ ) to remove particles before injection instead of filtration as trace amounts of PFHpA was found in the nylon syringe filter. The possible contamination from methanol and nitrogen was evaluated by evaporating $15 \mathrm{~mL}$ methanol to $1 \mathrm{~mL}$ under nitrogen stream for analysis and no target analyte was detectable.

The sample analysis for nine PFCs-perfluoroheptanoic acid (PFHpA), perfluorooctanoic acid (PFOA), perfluorononanoic acid (PFNA), perfluorodecanoic acid (PFDA), perfluorododecanoic acid (PFDoDA), perfluorotetradecanoic acid (PFTA), perfluoroundecanoic acid (PFUnDA), potassium salts of perfluorohexane sulfonate (PFHxS) and perfluorooctane sulfonate (PFOS) - was accomplished with high performance liquid chromatography equipped with an electrospray ionization tandem mass spectrometer (API 3200; Applied Biosystems/MDS SCIEX, US) (HPLC-ESI/MS/MS). Sodium perfluoro-1-(1, 2, 3, $\left.{ }_{4-}{ }^{13} \mathrm{C}_{4}\right)$ octanesulfonate $\left({ }^{13} \mathrm{C}_{4}\right.$-PFOS $)$ was used as the internal standard. PFCs were separated on a Dionex Acclaim $120 \mathrm{C} 18$ column $(5 \mu \mathrm{m}, 4.6 \mathrm{~mm}$ i.d. $\times 150 \mathrm{~mm}$ length; Dionex, Sunnyvale, CA, USA) with an aliquot of $10 \mu \mathrm{L}$ injection. A 10 min dualistic gradient of methanol and $50 \mathrm{mM} \mathrm{NH}{ }_{4} \mathrm{OAc}$ was optimized as follows: start at $28 \% 50 \mathrm{mM} \mathrm{NH}_{4} \mathrm{OAc}$. Reduce $\mathrm{NH}_{4} \mathrm{OAc}$ to $5 \%$ at $4 \mathrm{~min}$ before returning to the original condition at $7 \mathrm{~min}$. The

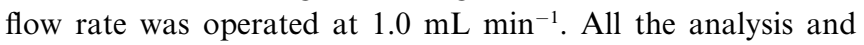
quantification was conducted using the ESI/MS/MS system operated in negative ion and MRM mode. The limits of detection (LODs) were $0.25 \mathrm{ng} \mathrm{g}^{-1}$ for PFHxS, $0.17 \mathrm{ng} \mathrm{g}^{-1}$ for PFOS, $0.5 \mathrm{ng}$ $\mathrm{g}^{-1}$ for PFHpA, PFOA, PFNA, PFDA and PFUnDA, $0.6 \mathrm{ng} \mathrm{g}^{-1}$ for PFDoDA, and $1.0 \mathrm{ng} \mathrm{g}^{-1}$ for PFTA. A standard calibration was conducted for every batch of analysis. A PFC standard of 1 $\mu \mathrm{g} \mathrm{\textrm {L } ^ { - 1 }}$ was employed as the quality control, and was checked every 10 injections to ensure the stability of analysis and for calibration verification. Only when the quality control standard was within $\pm 20 \%$ of its initial value, can the calibration curve be used for quantification. 
The TL of mollusks was determined according to a method in previous work based on nitrogen isotope ratios $\left(\delta^{15} \mathrm{~N}\right) .{ }^{27}$ The correlations among PFCs in mollusks were evaluated by Pearson's correlation two-tailed test using SPSS 13.0. During the test, samples were excluded when all the target analyte concentrations were below LODs.

\section{Results}

Most of the 137 pooled mollusk samples were found to contain detectable PFCs. The concentrations of PFCs in mollusk soft tissue are presented and discussed on a dry weight basis. Previous work has shown that PFOS was the most predominant PFC in various biotic matrixes and at higher levels than $\mathrm{PFOA}^{28}$ However, the prominent PFC in mollusks in the Bohai Sea is PFOA, as summarized in Table 1 and Fig. 2. Seventy-five percent of the samples were found to have measurable amounts of PFOA. Generally, the mean concentrations of PFOA $(<0.5 \sim 126$ ng $\mathrm{g}^{-1}, \mathrm{dw}$ ) were $1.5 \sim 46.9$ times higher than that of PFOS (Table 1), except Neverita didyma, in which PFOA was below the LOD. PFOS was detected in $61 \%$ of the mollusk samples; PFHxS was not found in any of the samples; and PFHpA was detected in $45 \%$ of the 137 samples, as shown in Table 1. PFNA, PFDA and PFUnDA were found only in a few samples $(<20 \%)$, they will not be regarded in the subsequent discussion.
Large variations of PFOA levels were observed among the eleven species (Fig. 3-a). Generally, concentrations of PFOA in mollusk samples were in the rank order; ark shell $\approx$ clam $>$ spiral shell $>$ mussel. Mactra veneriformis was found to have significantly higher levels of PFOA, which were $<0.5 \sim 111.0 \mathrm{ng} \mathrm{g}^{-1}$ (mean $31.3 \mathrm{ng} \mathrm{g}^{-1}, \mathrm{dw}$ ), followed by Scapharca subcrenata and Meretrix meretrix Linnaeus, in which the PFOA concentrations were $<0.5 \sim 40.5 \mathrm{ng} \mathrm{g}^{-1}$ (mean $9.96 \mathrm{ng} \mathrm{g}^{-1}$, dw) and $<0.5 \sim 25.3 \mathrm{ng}$ $\mathrm{g}^{-1}$ (mean $6.97 \mathrm{ng} \mathrm{g}^{-1}, \mathrm{dw}$ ), respectively. Concentrations of PFOA were significantly higher in Mactra veneriformis, Scapharca subcrenata and Meretrix meretrix Linnaeus, compared with those in the other species. It should be noted that the wide range of PFOA contents $\left(<0.5 \sim 126 \mathrm{ng} \mathrm{g}^{-1}\right)$ in Neverita didyma was owing to the extremely high concentrations detected in only three samples (19.0 $\mathrm{ng} \mathrm{g}^{-1}, 44.9 \mathrm{ng} \mathrm{g}^{-1}$ and $126 \mathrm{ng} \mathrm{g}^{-1}$ ). However, the median value was $<0.5 \mathrm{ng} \mathrm{g}^{-1}$ and thus these three samples were identified as extreme values and excluded when mean concentrations were evaluated and discussed.

In the present study, the concentrations of PFOS and $\mathrm{PFHpA}$ were much lower than those of PFOA (Fig. 3). The ratio of PFOA/PFOS was found to be as great as 45.9 in Meretrix meretrix Linnaeus. The highest level of PFOS was found in Mactra veneriformis, which was $1.24 \mathrm{ng} \mathrm{g}^{-1}\left(0.30 \mathrm{ng} \mathrm{g}^{-1} \sim 2.56 \mathrm{ng} \mathrm{g}^{-1}\right.$, $\mathrm{dw})$, whereas the second highest concentration was in Neverita didyma (mean $0.92 \mathrm{ng} \mathrm{g}^{-1}$, dw) (Table 1).

Table 1 Concentrations of nine PFCs in mollusk soft tissue samples from the Bohai Sea (ng $\left.\mathrm{g}^{-1}, \mathrm{dw}\right)$

\begin{tabular}{|c|c|c|c|c|c|c|}
\hline Species & & PFOA & PFOS & PFHpA & PFDA & PFUnDA \\
\hline \multirow[t]{3}{*}{ Crassostrea talienwhanensis } & detected $^{a}$ & $5 / 9$ & $6 / 9$ & $4 / 9$ & $2 / 9$ & $1 / 9$ \\
\hline & mean $^{b}$ & 1.70 & 0.70 & 0.71 & - & - \\
\hline & range & $<0.5 \sim 11.1$ & $<0.17 \sim 3.80$ & $<0.5 \sim 2.02$ & $<0.5 \sim 1.65$ & $<0.5 \sim 0.59$ \\
\hline \multirow[t]{3}{*}{ Chlamys farreri } & detected & $5 / 5$ & $4 / 5$ & $3 / 5$ & $1 / 5$ & - \\
\hline & mean & 1.86 & 0.47 & 0.80 & - & - \\
\hline & range & $1.0 \sim 3.02$ & $<0.17 \sim 0.82$ & $<0.5 \sim 1.50$ & $<0.5 \sim 0.56$ & - \\
\hline \multirow[t]{3}{*}{ Amusium } & detected & $8 / 8$ & $2 / 8$ & $8 / 8$ & $1 / 8$ & - \\
\hline & mean & 1.76 & - & 1.43 & - & $<0.5$ \\
\hline & range & $0.54 \sim 6.22$ & $<0.17 \sim 0.24$ & $0.5 \sim 4.00$ & $<0.5 \sim 0.82$ & - \\
\hline \multirow[t]{3}{*}{ Scapharca subcrenata } & detected & $16 / 17$ & $15 / 17$ & $4 / 17$ & $4 / 17$ & $8 / 17$ \\
\hline & mean & 15.0 & 0.60 & - & 0.64 & 0.53 \\
\hline & range & $<0.5 \sim 110$ & $<0.17 \sim 2.78$ & $<0.5 \sim 5.0$ & $<0.5 \sim 2.06$ & $<0.5 \sim 1.28$ \\
\hline \multirow[t]{3}{*}{ Meretrix meretrix Linnaeus } & detected & $20 / 23$ & $11 / 23$ & $14 / 23$ & $4 / 23$ & $3 / 23$ \\
\hline & mean & 12.2 & 0.26 & 1.10 & 0.57 & - \\
\hline & range & $<0.5 \sim 69.1$ & $<0.17 \sim 0.50$ & $<0.5 \sim 3.89$ & $<0.5 \sim 2.94$ & $<0.5 \sim 0.56$ \\
\hline \multirow[t]{3}{*}{ Mactra veneriformis } & detected & $5 / 7$ & $7 / 7$ & $4 / 7$ & $3 / 7$ & $3 / 7$ \\
\hline & mean & 31.3 & 1.24 & 1.06 & 0.76 & 0.50 \\
\hline & range & $<0.5 \sim 111$ & $0.30 \sim 2.56$ & $<0.5 \sim 2.64$ & $<0.5 \sim 1.50$ & $<0.5 \sim 0.83$ \\
\hline \multirow[t]{3}{*}{ Mactra chinensis } & detected & $2 / 4$ & $4 / 4$ & $3 / 4$ & - & - \\
\hline & mean & 1.08 & 0.70 & 0.87 & $<0.5$ & $<0.5$ \\
\hline & range & $<0.5 \sim 2.30$ & $0.57 \sim 0.96$ & $<0.5 \sim 1.23$ & - & - \\
\hline \multirow[t]{3}{*}{ Mya arenaria } & detected & $3 / 6$ & $1 / 6$ & $2 / 6$ & - & - \\
\hline & mean & 0.64 & - & - & $<0.5$ & $<0.5$ \\
\hline & range & $<0.5 \sim 1.23$ & $<0.17 \sim 0.20$ & $<0.5 \sim 1.30$ & - & - \\
\hline \multirow[t]{3}{*}{ Neverita didyma } & detected & $9 / 19$ & $17 / 19$ & $3 / 19$ & $4 / 19$ & $7 / 19$ \\
\hline & mean & $<0.5$ & 0.92 & - & - & 0.58 \\
\hline & range & $<0.5 \sim 126$ & $<0.17 \sim 4.33$ & $<0.5 \sim 1.51$ & $<0.5 \sim 3.17$ & $<0.5 \sim 1.69$ \\
\hline \multirow[t]{3}{*}{ Rapana venosa } & detected & $14 / 24$ & $9 / 24$ & $10 / 24$ & $2 / 24$ & - \\
\hline & mean & 2.38 & 0.22 & 0.58 & - & - \\
\hline & range & $<0.5 \sim 33.0$ & $<0.17 \sim 0.58$ & $<0.5 \sim 1.46$ & $<0.5 \sim 3.43$ & - \\
\hline \multirow[t]{3}{*}{ Mytilus edulis } & detected & $12 / 15$ & $7 / 15$ & $6 / 15$ & $3 / 15$ & $1 / 15$ \\
\hline & mean & 1.96 & 0.26 & 0.88 & - & - \\
\hline & range & $<0.5 \sim 12.2$ & $<0.17 \sim 0.55$ & $<0.5 \sim 3.32$ & $<0.5 \sim 1.74$ & $<0.5 \sim 0.97$ \\
\hline
\end{tabular}

${ }^{a}$ Represents the ratio of samples greater than the LOD. ${ }^{b}$ Concentrations below the LOD were assigned as LOD/ $\sqrt{2}$ when mean concentrations were calculated. However, mean concentrations were not evaluated when the detected frequency of some analytes was too low. 

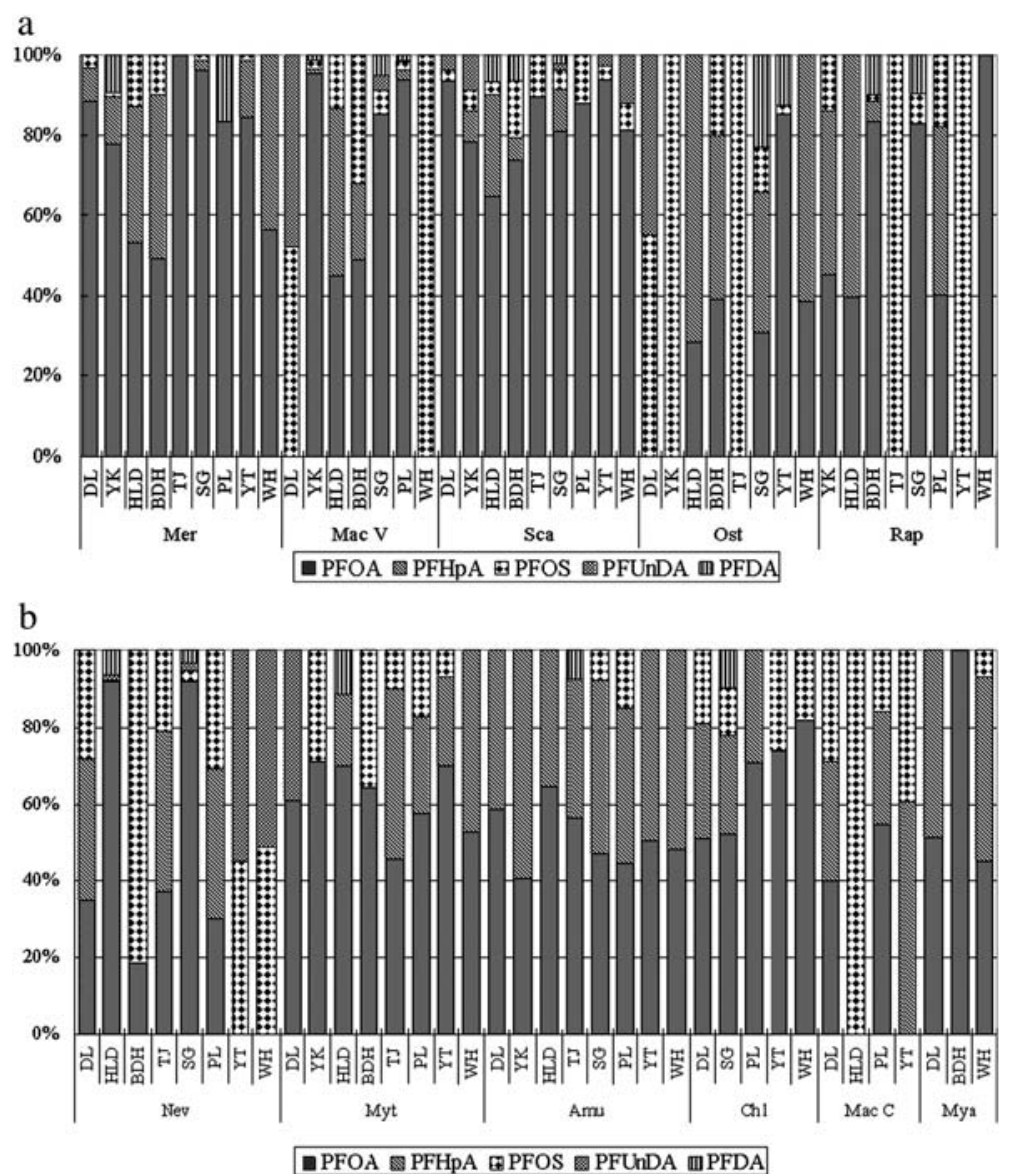

Fig. 2 Composition profiles of perfluorinated compounds in mollusk soft tissue.
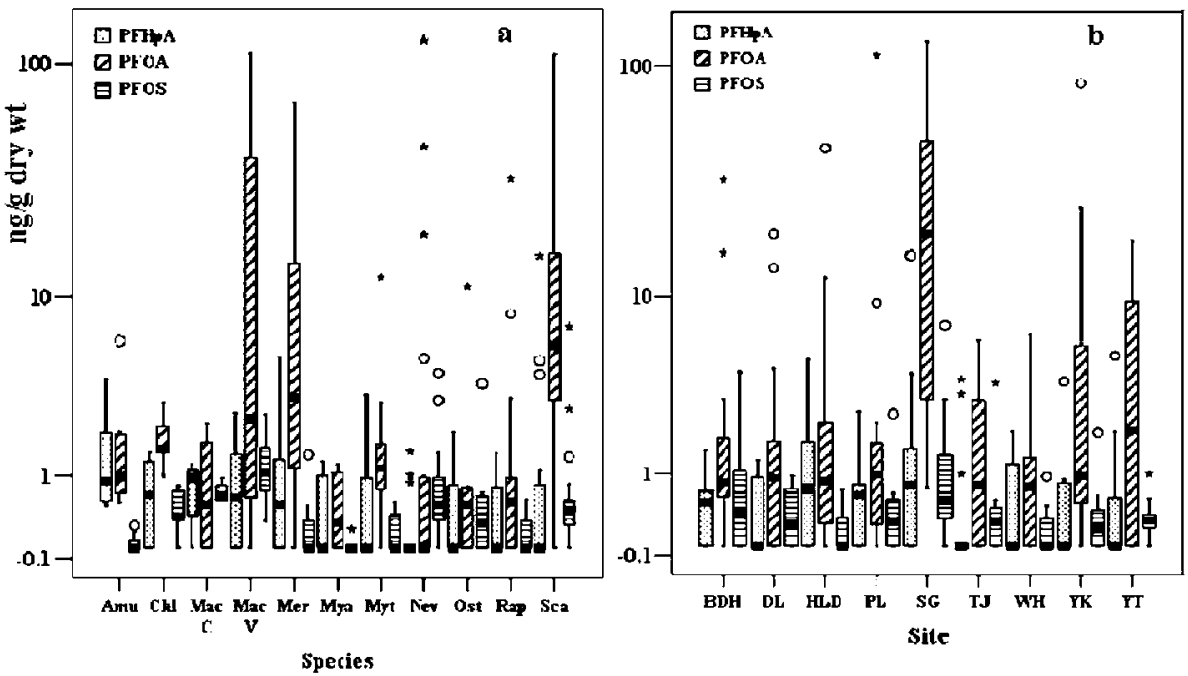

Fig. 3 Box-and-whisker plots of PFCs in mollusks collected from the coastal water of the Bohai Sea (ng g ${ }^{-1}$, dw) (a: different species; b: different sampling sites). The horizontal black line in the boxes represents the median value and the lower and upper edge of the box marks the 25th and 75th percentiles. The whiskers extending from the box show the highest and lowest values. $\star$ represents extreme values, which were beyond the triplication of the difference between 25 th and 75 th percentiles, and singular values are represented by $\bigcirc$, which were beyond the 150 th percentile of the difference between 25 th and 75 th percentiles. 
As shown in Fig. 3-b, among the sampling sites, SG should be paid more attention than other sites as the highest concentration of the individual analytes was mostly found in this area in each species. According to Fig. 3-b, the second and third highest levels of PFOA were observed in YT and YK, respectively. Higher levels of PFOA suggest higher emissions or use of products containing PFCs and related compounds in the sampling sites. When considering the mean concentrations of $\sum$ PFHpA + PFOA + PFOS for the sampling sites, the highest value was also found in SG (35.3 $\left.\mathrm{ng} \mathrm{g}^{-1}, \mathrm{dw}\right)$, followed by YK (11.2 $\left.\mathrm{ng} \mathrm{g}^{-1}, \mathrm{dw}\right)$ and PL (10.1 $\left.\mathrm{ng} \mathrm{g}^{-1}, \mathrm{dw}\right)$, while slight difference was found in the mean values of the other six sampling sites $\left(2.25-6.58 \mathrm{ng} \mathrm{g}^{-1}, \mathrm{dw}\right)$.

\section{Discussion}

The different levels among species is likely due to different diet/ metabolism or exposure differences around their residence. However, the relatively higher concentrations in some mollusks may reflect their potential higher bioaccumulation capacity for PFOA, as some precursors can be metabolized to PFOA and other related PFCs. The metabolic capabilities have been shown to influence the concentration of several organic pollutants in seabirds. ${ }^{29}$ Among the eleven species, only Neverita didyma and Rapana venosa are detrivorous, while the others are all filter feeders, feeding mainly on unicellular algae, microorganisms and marine humus. It is assumed that PFCs can bioaccumulate along the food web, ${ }^{27}$ but Neverita didyma and Rapana venosa were found to contain very low levels of PFOA and PFOS (Table 1). A negative correlation between the $\sum$ PFCs (PFHpA, PFOA and PFOS) and the trophic levels (TL) were found for the mollusks, although the linear correlation was not significant $(p>0.05)$ (Fig S1. Supplementary Information $\dagger$ ).

PFHpA, PFOA and PFOS were found to be significantly correlated with each other $(p<0.01, n=123)$, with the Pearson's correlation coefficients for PFHpA-PFOA at 0.419, PFOA-PFOS 0.578 and PFHpA-PFOS 0.480. The fact that PFHpA, PFOA and PFOS were correlated with each other might be a favorable proof for the hypothesis that these compounds have a common source or similar transformation mechanism in the Bohai Sea region. Marine foods including oysters and mussels are often involved in studies as potential bioindicators/biomonitors related to aquatic contamination. ${ }^{20,21,25}$ Studies on PFC concentrations in mollusks, however, are very scarce. The profile patterns of PFCs in mollusks from the Bohai Sea were found to be different from previous studies in coastal cities in south China ${ }^{18}$ and the eastern Arctic, ${ }^{29}$ where PFOS was found to the predominant PFC. The dominance of PFOA has also been found in aquatic organisms from the Ariake Sea of Japan. ${ }^{30}$ The detailed reason why PFOA is the predominant contaminant still remains unclear, but these findings at least demonstrated the different pollution sources of PFCs in these areas. It has been reported that in DL coastal water PFOA is the main PFC, ${ }^{19}$ indicating a potential relationship between PFCs in sea water and the habitat of the mollusks.

Oysters and mussels are more frequently used than other mollusks in past studies on marine PFC contamination. Previous research conducted with oysters (Crassostrea virginica) from the Gulf of Mexico and Chesapeake Bay showed extremely high PFOS concentrations ( $<42$ to $\left.1225 \mathrm{ng} \mathrm{g}^{-1}\right) \cdot{ }^{31}$ Conversely, in this work all the PFCs detected in mollusks were normally at low levels. The PFOA level $\left(1.70 \mathrm{ng} \mathrm{g}^{-1}, \mathrm{dw}\right)$ in Crassostrea talienwhanensis was much lower than that found in Tokyo Bay, ${ }^{17}$ but similar to that in the Ariake Sea, ${ }^{30}$ while PFOS concentration was slightly higher than in south China ${ }^{18}$ and the Eastern Arctic. ${ }^{29}$ When considering mussels (Mytilus edulis), concentrations of PFOA and PFOS were $1.96 \mathrm{ng} \mathrm{g}^{-1}$ and $0.26 \mathrm{ng} \mathrm{g}^{-1}$ (mean, $\mathrm{dw}$ ), respectively, which are comparable to those in south China, ${ }^{18}$ so were those of PFOA in the Ariake Sea, ${ }^{30}$ while PFOS was not detectable in mussels in the Ariake Sea. The current finding in DL showed that only PFOS was detected in oysters (Crassostera talienwhanensis, $0.71 \mathrm{ng} \mathrm{g}^{-1}, \mathrm{dw}$ ) and PFOA in mussels (Mytilus edulis, $1.03 \mathrm{ng} \mathrm{g}^{-1}, \mathrm{dw}$ ), which is lower compared with that in Japan and the south of China, ${ }^{17}$ although PFCs were at similar levels in coastal waters in the corresponding regions. ${ }^{17,19}$ The average PFOA and PFOS concentrations when considering all species were $7.36 \mathrm{ng} \mathrm{g}^{-1}(\mathrm{dw})$ and $0.46 \mathrm{ng} \mathrm{g}^{-1}(\mathrm{dw})$, respectively. The results were slightly higher than those detected in south China and eastern Arctic, ${ }^{18,29}$ but PFOA concentration levels were lower than those found in Tokyo Bay and the Ariake Sea in Japan. ${ }^{17,30}$

As far as we know, past studies have not reported specifically high levels of PFCs in clams; PFOA was not detectable in clams in the eastern Arctic, ${ }^{29}$ and PFOA concentrations in clams were similar to other species in the Ariake Sea. ${ }^{30}$ However, in this present study, clams were found to contain significantly higher concentrations of PFOA than other species (Table 1 and Fig.3-a).

Dietary intake has been supposed to be an important contributor of human exposure of PFCs. A recent survey on the human exposure to PFCs through the diet carried out in Spain suggested that fish was the main contributor to PFOS in human beings. ${ }^{7}$ In this work, risk assessment based on dietary intake of mollusks for the local residents was conducted on the basis of the study by Gulkowsaka et al. ${ }^{18}$ Since investigations on the daily consumption of related mollusks was not conducted in the sampling locations, data collected in Zhoushan, which is also a coastal city, was adopted for reference in the present study. ${ }^{18}$ The daily consumption ( $\mathrm{g}$ per person, wet weight) of bivalves (mussels, oysters, and clams) was estimated to be $76 \mathrm{~g}$ for the Zhoushan population (1172 $\mathrm{g}$ total intake/day). In the present study, using the highest concentrations of PFOS (4.33 $\left.\mathrm{ng} \mathrm{g}^{-1}\right)$ and PFOA (126 ng g (Table 1) results in an average daily intake (ADI) of $\leq 0.0011 \mu \mathrm{g}$ PFOS $\mathrm{kg}^{-1} \mathrm{~d}^{-1}$ and $\leq 0.032 \mu \mathrm{g}$ PFOA kg $\mathrm{kg}^{-1} \mathrm{~d}^{-1}$. The Provisional Reference Dose (RfDs) value for PFOS was estimated to be at $0.025 \mu \mathrm{g} \mathrm{kg}^{-1} \mathrm{~d}^{-1}$, and that for PFOA was $0.333 \mu \mathrm{g} \mathrm{kg}^{-1} \mathrm{~d}^{-1}$ based on study results from rats. ${ }^{32}$ Therefore it is concluded that the local people are not likely to be significantly exposed to PFCs through the consumption of mollusks in the Bohai Sea.

In summary, PFCs could be detected in mollusks in the Bohai Sea of China, with PFOA as the prominent pollutant. The Bohai Sea region is considered not to be severely polluted compared with other studied regions around the world. As suggested in this present work, subsequent studies should be carried out in order to clarify the potential causes of the high PFC contamination in $\mathrm{SG}$, and further understand PFC distribution and temporal trends in mollusks.

\section{Acknowledgements}

This work was jointly supported by the High-Technology Research and Development Program of China (2007AA06Z405), 
the Major Research Program of Chinese Academy of Sciences (No. KZCX2-YW-420-1), the National Natural Science Foundation of China (No. 20621703, 20837003) and the National Basic Research Program of China (2009CB421605).

\section{References}

1 C. L. Tseng, L. L. Liu, C. M. Chen and W. H. Ding, J. Chromatogr., $A, 2006, \mathbf{1 1 0 5}, 119$.

2 M. K. So, N. Yamashita, S. Taniyasu, Q. Jiang, J. P. Giesy, K. Chen and P. K. S. Lam, Environ. Sci. Technol., 2006, 40, 2924.

3 D. A. Ellis, D. Mackay, J. Butler, C. McMurdo, Water bodies are a source of PFCAs not just a sink, Society of Environmental Toxicology and Chemistry North America Meeting, Montreal, Canada, 2006.

4 J. W. Martin, K. Kannan, U. Berger, P. D. Voogt, J. Field, J. Franklin, J. P. Giesy, T. Harner, D. C. G. Muir, B. Scott, M. Kaiser, U. Järnberg, K. C. Jones, S. A. Mabury, H. Schroeder, M. Simcik, C. Sottani, B. V. Bavel, A. Kärrman, G. Lindström and S. V. Leeuwen, Environ. Sci. Technol., 2004, 38, 248A.

5 C. A. Moody, J. W. Martin, W. C. Kwan, D. C. G. Muir and S. A. Mabury, Environ. Sci. Technol., 2002, 36, 545.

6 M. K. So, Y. Miyake, W. Y. Yeung, Y. M. Ho, S. Taniyasu, P. Rostkowski, N. Yamashita, B. S. Zhou, X. J. Shi, J. P. Giesy, H. Yu and P. K. S. Lam, Chemosphere, 2007, 68, 2085.

7 I. Ericson, M. Gomez, M. Nadal, B. Van Bavel, G. Lindström and J. L. Domingo, J. Agric. Food Chem., 2008, 56, 1787.

8 K. Kannan, L. Tao, E. Sinclair, S. D. Pastva, D. J. Jude and J. P. Giesy, Arch. Environ. Contam. Toxicol., 2005, 48, 559.

9 M. Shoeib, T. Harner and P. Vlahos, Environ. Sci. Technol., 2006, 40, 7577.

10 C. Lau, K. Anitole, C. Hodes, D. Lai, A. Pfahles-Hutchens and J. Seed, Toxicol. Sci., 2007, 99, 366.

11 K. D. Oakes, P. K. Sibley, K. R. Solomon, S. A. Mabury and G. J. Van der Kraak, Environ. Toxicol. Chem., 2004, 23, 1912.

12 B. J. Apelberg, F. R. Witter, J. B. Herbstman, A. M. Calafat, R. U. Halden, L. L. Needham and L. R. Goldman, Environ. Health Perspect., 2007, 115, 1670.

13 T. Wang, Y. W. Wang, C. Y. Liao, Y. Q. Cai and G. B. Jiang, Environ. Sci. Technol., 2009, 43, 5171.
14 N. Saito, K. Sasaki, K. Nakatome, K. Harada, T. Yoshinaga and A. Koizumi, Arch. Environ. Contam. Toxicol., 2003, 45, 149.

15 E. Sinclair and K. Kannan, Environ. Sci. Technol., 2006, 40, 1408 .

16 A. Jahnke, S. Huber, C. Temme, H. Kylin and U. Berger, J. Chromatogr., A, 2007, 1164, 1.

17 M. K. So, S. Taniyasu, P. K. S. Lam, J. Zheng, J. P. Giesy and N. Yamashita, Arch. Environ. Contam. Toxicol., 2006, 40, 240.

18 A. Gulkowsaka, Q. Jiang, M. K. So, S. Taniyasu, P. K. S. Lam and N. Yamashita, Environ. Sci. Technol., 2006, 40, 3736.

19 X. D. Ju, Y. H. Jin, K. Sasaki and N. Saito, Environ. Sci. Technol., 2008, 42, 3538.

20 L. N. Liang, J. B. Shi, B. He, G. B. Jiang and C. G. Yuan, J. Agric. Food Chem., 2003, 51, 7373.

21 R. Q. Yang, Q. F. Zhou, J. Y. Liu and G. B. Jiang, Food Chem., 2006, 97, 637.

22 Y. Wan, J. Y. Hu, K. Zhang and L. H. An, Environ. Sci. Technol,, 2008, 42, 1078

23 3M, 3M Laboratory Report E00-13 11; U. S. Environmental Protection Agency, Docket AR 226-1030a030, 2000.

24 K. J. Hansen, H. O. Johnson, J. S. Eldridge, J. L. Butenhoff and L. A. Dick, Environ. Sci. Technol., 2002, 36, 1681.

25 Y. W. Wang, T. Wang, A. Li, J. J. Fu, P. Wang, Q. H. Zhang and G. B. Jiang, Environ. Sci. Technol., 2008, 42, 7159.

26 Y. W. Wang, R. Q. Yang and G. B. Jiang, Environ. Pollut., 2007, 146, 100.

27 Y. W. Wang, X. M. Li, A. Li, T. Wang, Q. H. Zhang, P. Wang, J. J. Fu and G. B. Jiang, Environ. Sci. Technol., 2007, 41, 6026.

28 L. W. Y. Yeung, M. K. So, G. B. Jiang, S. Taniyasu, N. Yamashita, M. Y. Song, Y. N. Wu, J. G. Li, J. P. Giesy, K. S. Guruge and P. K. S. Lam, Environ. Sci. Technol., 2006, 40, 715.

29 T. G. Tomy, W. Budakowski, T. Halldorson, P. A. Helm, G. A. Stern, K. Friesen, K. Pepper, S. A. Tittlemier and A. T. Fisk, Environ. Sci. Technol., 2004, 38, 6475.

30 H. Nakata, K. Kannan, T. Nasu, H. Cho, E. Sinclair and A. Takemura, Environ. Sci. Technol., 2006, 40, 4916.

31 K. Kannan, K. J. Hansen, T. L. Wade and J. P. Giesy, Arch. Environ. Con. Tox., 2002, 42, 313.

32 K. Thayer, Environmental Working Group: Washington, D.C., 2002, 41, 3109 . 